\title{
Erratum to: Application of WetSpass model to estimate groundwater recharge variability in the Nile Delta aquifer
}

\author{
Asaad M. Armanuos ${ }^{1}$ - Abdelazim Negm ${ }^{2}$ C. Yoshimura $^{3}$. \\ Oliver C. Saavedra Valeriano ${ }^{4}$
}

Published online: 1 August 2016

(C) Saudi Society for Geosciences 2016

Erratum to: Arab J Geosci

DOI 10.1007/s12517-016-2580-x

The original version of this article, unfortunately, contained errors. In Fig. 7, the year in each panel images were incorrect. Given in this article is the correct Fig. 7.

The online version of the original article can be found at doi:http://dx.doi. org/10.1007/s12517-016-2580-x.

Asaad M. Armanuos

asaad.matter@ejust.edu.eg

Abdelazim Negm

amnegm@zu.edu.eg; negm@ejust.edu.eg

C. Yoshimura

yoshimura.c.aa@m.titech.ac.jp

Oliver C. Saavedra Valeriano

oliversaavedra@upb.edu

1 Environmental Engineering Department, School of Energy and

Environmental Engineering, Egypt-Japan University of Science and
Technology, E-JUST, Alexandria (Faculty of Engineering, Tanta University), Alexandria, Egypt

2 Environmental Engineering Department, School of Energy and Environmental Engineering, Egypt-Japan University of Science and Technology, E-JUST, Alexandria (Seconded from Zagazig University, P.O. Box 179, New Borg Al-Arab City, Alexandria Postal Code 21934, Egypt

3 Department of Civil Engineering, Tokyo Institute of Technology, 2-12-1 Ookayama, Meguro, Tokyo 152-0033, Japan

4 Civil Engineering Research Center, Universidad Privada Boliviana, Cochabamba, Bolivia 


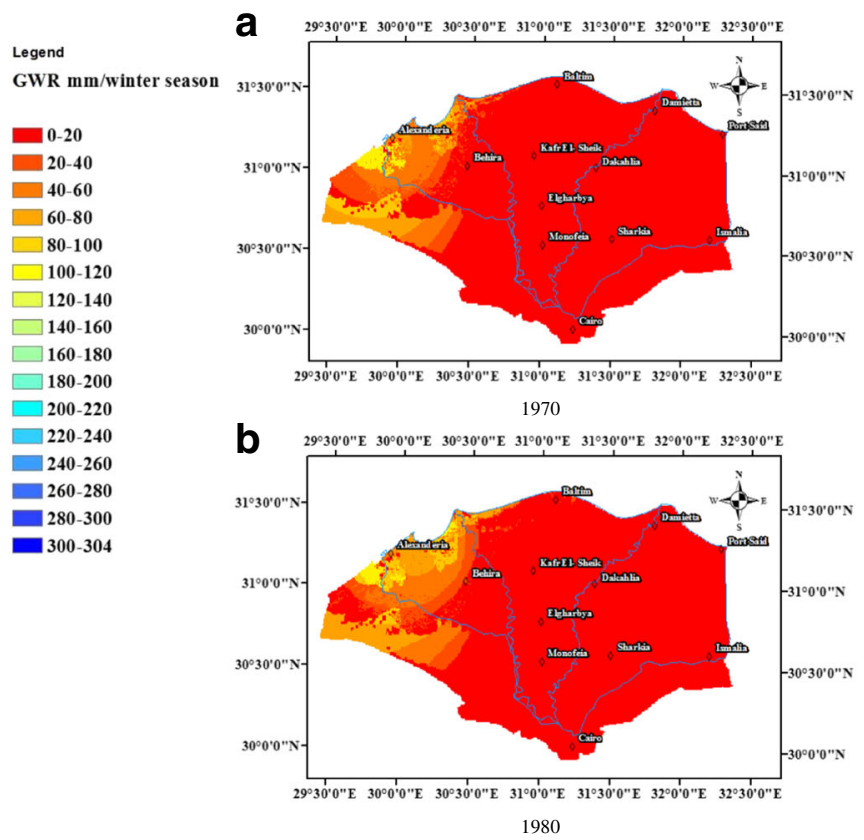

Legend

GWR mm/winter seaso

\section{0-20}

20-40

$\square$ 40-60

60-80

$\square$ 80-100

$\square$ 100-120

$\square$ 120-140

$\square$
$\square 180-180$
$\square \quad 180-200$

$\square$ 200-220

$\square$ 220-240

$\square$ 240-260

$240-260$
$-260-280$

280-300

-300-304

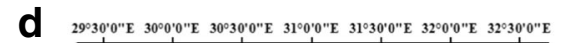

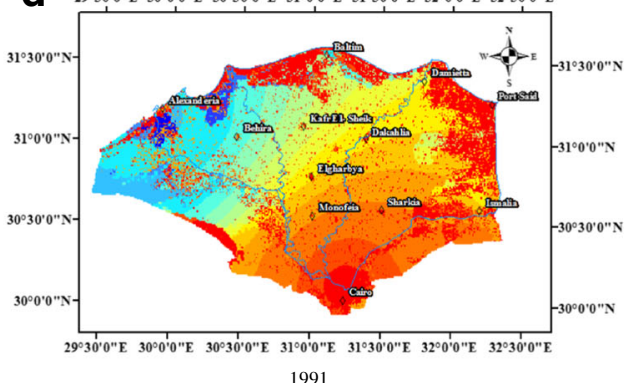

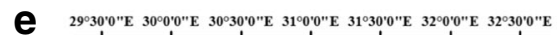
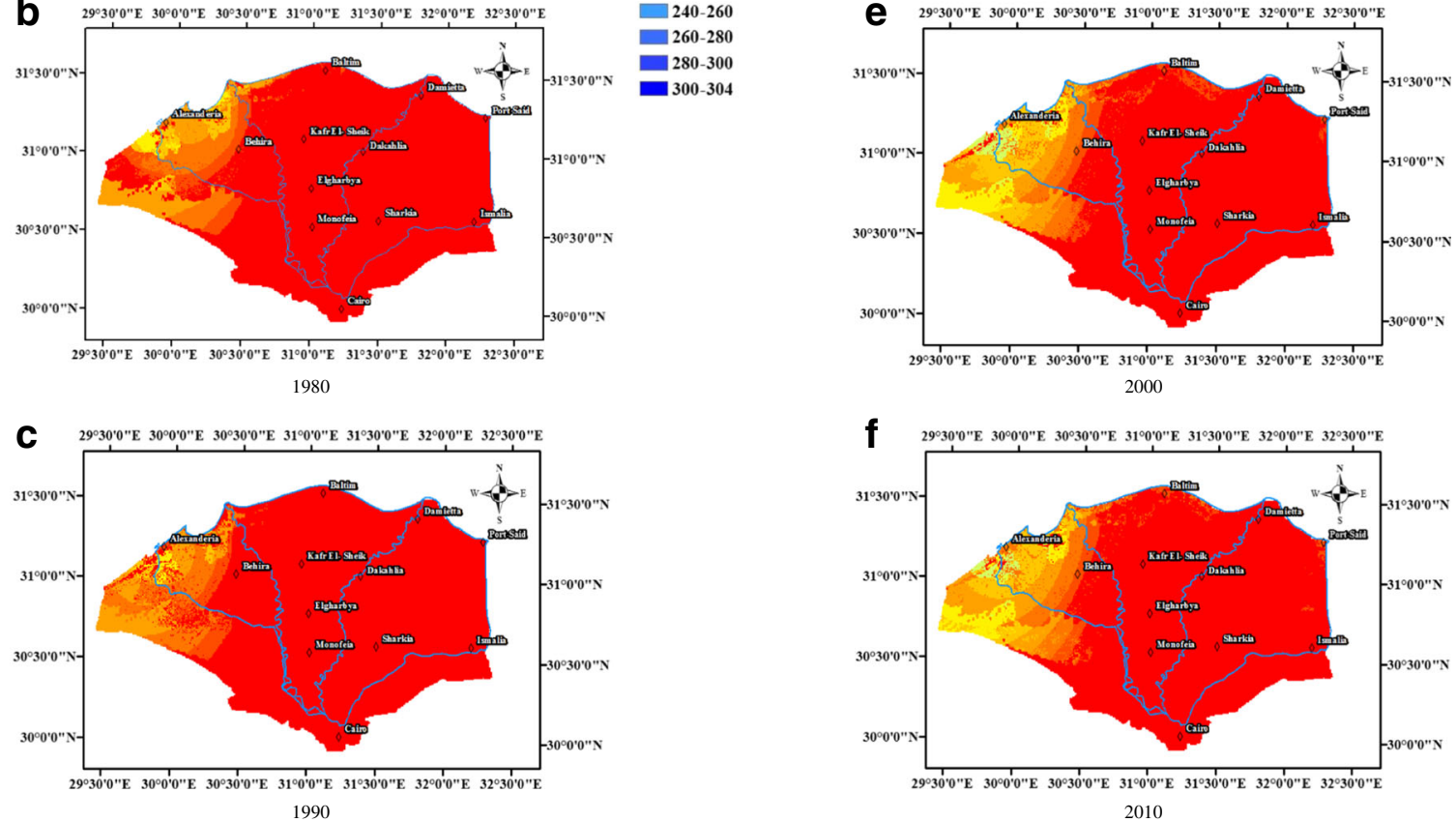